\title{
Pharmacovigilance adverse drug reactions reporting: knowledge, attitude and practice study among health professionals in Yaoundé, Cameroon
}

\begin{abstract}
Pharmacovigilance has become an important component of drug development of phytomedicine in sub Saharan Africa. The term pharmacovigilance means all scientific and data gathering activities relating to the detection, assessment, and understanding of adverse events. These activities are undertaken with the goal of identifying adverse events and understanding, their nature, frequency, and potential risk factors. In developing countries there is a gap of information on data outcome of adverse reaction of most approved drugs in the market. This study was therefore conducted with the aim to evaluate the educational needs (knowledge gap) of health professionals in Yaoundé, Cameroon towards adverse drug reactions reporting. The study design was a cross sectional study conducted in three hospitals in Yaoundé, the capital of Cameroon, in thirteen community pharmacies. A pre-tested self- administered questionnaire was used to assess knowledge, attitudes and practices of participants. The study was carried from the 4th of November 2013 to 25 April 2014. The data were analyzed using SPSS Version 18.0 and Microsoft Excel 2007 software. A total of 330 health professionals were enrolled in the study. One hundred and eightyeight participants with 50 physicians (26.6\%), 14 pharmacists $(7.4 \%), 2$ dentists $(1.1 \%)$, 112 nurses $(59.6 \%)$ and 10 midwives $(5.3 \%)$ completed the questionnaire. Seventy-eight respondents out of one hundred and eighty-eight knew about the existence of a National Pharmacovigilance Centre. Sixty-seven nurses and six midwives were aware of the adverse drug reactions reporting system. The knowledge score of one hundred and forty seven $(782 \%)$ health professionals in our sample was poor and 45 health professionals $(23.9 \%)$ who had a very low level of knowledge. Respondents recognized almost unanimously $(94.7 \%)$ that adverse drug reactions reporting were necessary. Similarly, one hundred and seventy-one practitioners $(91 \%)$ believed that adverse drug reaction reporting was obligatory. The knowledge, attitudes and practices of health professional towards adverse drug reactions reporting were poor in our study population. As a direct consequence, the adverse drug reactions reporting rate was very low.
\end{abstract}

Keywords: adverse drug reaction, health professionals; knowledge, attitude, practice, pharmacovigilance, reporting, Cameroon
Volume 4 Issue 6 - 2017

\author{
Fokunang Charles, ${ }^{1,2,3,4}$ Djousse Ngnimpa \\ Christian,' Tembe Fokunang Estella, ${ }^{2}$ Kechia \\ Frederick, ${ }^{3}$ Ndikum Valentine,' Ngadou \\ Peggy, ${ }^{2}$ Abondo Ngono Mbala Rose ${ }^{2}$ \\ 'Department of Biochemistry, University of Yaoundé, Cameroon \\ ${ }^{2}$ Department of Pharmaco-toxicology and \\ Pharmacokinetic, University of Yaoundé, Cameroon \\ ${ }^{3}$ Department of Clinical Sciences, University of \\ Bamenda, Cameroon \\ ${ }^{4}$ Department of Biological Sciences, University of \\ Bamenda, Cameroon
}

\section{Correspondence: Charles Fokunang, Department of Pharmaco-toxicology and Pharmacokinetic, Faculty of Medicine and Biomedical Sciences, University of Yaound, Tel +237} 670902446, Email charlesfokunang@yahoo.co.uk

Received: January 24, 2017 | Published: May 26, 2017
Abbreviations: ADR, adverse drug reactions; WHO, world health organization; HP, health practitioners; NPVC, national pharmacovigilance centre; DPML, direction of pharmacy, medicine and laboratories; KAP, knowledge, attitudes and practices

\section{Introduction}

The term pharmacovigilance means all scientific and data gathering activities relating to the detection, assessment, and understanding of adverse events. These activities are undertaken with the goal of identifying adverse events and understanding, their nature, frequency, and potential risk factors. ${ }^{1}$ In developing countries there is a gap of information on data outcome of adverse reaction of most approved drugs in the market. This may be due to postmarketing sensitization by the medical delegates or by the medics administering the drugs to inform patients to report any problems linked to the drug during administration. ${ }^{1,2}$ There is therefore the need to understand the knowledge gap in pharmacovigilance among patients and stake holders of drug use. Post-marketing surveillance, phamacovigilance and adverse event/adverse experience are related to any untoward medical occurrence that may present during treatment with a pharmaceutical product but which does not necessarily have a causal relationship with this treatment. ${ }^{3}$ Reported information on a possible causal relationship between an adverse event and a drug, the relationship being unknown or incompletely documented previously in most cases more than a single report is required to generate a signal, depending upon the seriousness of the event and the quality of the information. ${ }^{3,4}$ We may have to trace back the need for pharmacovigilance studies from the disaster experience of thalidomide that was supposed to be a harmless sedative for expectant mothers, but instead thalidomide caused thousands of babies to be born with severe birth defects. ${ }^{2,5}$ The safety of drug is monitored through pre-clinical studies, organ toxicity, chronic toxicity , carcinogenicity , mutagenicity, teratogenicity. ${ }^{6}$ In Clinical studies involving Phases I, II, III, IV and in Post-marketing surveillance of ADR through Pharmacovigilance activities. The data can also be collected for other purposes such as routine statistics, databases of prescription and outcomes.

Limitations of pre-clinical studies and clinical trials Information obtained prior to first marketing is inadequate to cover all aspects of drug safety: tests in animals are insufficiently predictive of human safety, as efficacy is the major focus of drug clinical trials; short duration of clinical trials and risk of long term adverse effects. ${ }^{6}$

Other justification for PV studies are due to the fact that in clinical trials patients are selected and limited in number, special groups (such as children, the elderly or pregnant women) are not included in clinical trials, conditions of use in trials differ from those in clinical 
practice, duration of trials is limited for the obtention of information about rare but serious adverse reactions, chronic toxicity, and data drug interactions is often not available in classical clinical trial. ${ }^{6,8}$

Rationale for Post-marketing surveillance of ADR Post-marketing surveillance is needed in every country, because there are differences between countries in the occurrence of adverse drug reactions because of differences in: drug production, distribution and use (e.g. indications, dose, availability), genetics, diet, traditions of the people pharmaceutical quality and composition (excipients) of locally produced pharmaceutical products the use of non-orthodox drugs (e.g. herbal remedies) which may pose special toxicological problems, when used alone or in combination with other drugs. ${ }^{2,8}$

The need for an Adverse Drug reactions (ADR) monitoring system was stimulated by many events among which the most decisive seems to be the thalidomide disaster, with phocomelia observed in children born to mothers who received the non-barbiturate hypnotic placed on the market in 1956 and used in pregnant women. ${ }^{1,6}$ The detection of more than 7000 cases motivated the withdrawal of the thalidomide drug from the market in 1960. This drama encouraged the establishment in 1968 of the World health organization (WHO) Programme for International Drug Monitoring (WHO Drug Monitoring Centre). The World Health Organization (WHO) defines PV as a science or activities related to the detection, assessment, understanding and prevention of risks of adverse drug reactions (ADR) or any other drugs related problem. ${ }^{1,2}$ Indeed, the use of drugs exposed to a number of Risks Including ADR. These effects are responsible for a significant level of morbidity and mortality. ${ }^{2}$ Lazarou et al. ${ }^{3}$ concluded in 1998 that adverse reactions alone, excluding medication errors were responsible for more than 100000 deaths in 1994 and constituted between the fourth and sixth leading cause of death in the United States. ADR are responsible for $5.3 \%$ of hospital admissions. ${ }^{4}$

In order to better manage theses ADR, health systems-have opted for post marketing surveillance or $\mathrm{PV}$, today recognize by the WHO as an effective mean of drug risk management after the Issuance of the Marketing Authorization. ${ }^{4,5}$ However, PV systems in most countries face under reporting that prevents it to fully play its role. ${ }^{6}$. The main cause of low reporting rate is lack of information which results from inadequate training of health practitioners (HP). ${ }^{2}$ The aim of this study was to assess the knowledge, attitude and practices of HP in Yaoundé towards ADR reporting in PV.

\section{Methodology}

A cross-sectional study was conducted among HP practicing in selected institutions. Three Hospitals in Yaoundé, namely Yaoundé Central Hospital, the Yaoundé University Teaching Hospital, the Efoulan District Hospital and thirteen pharmacies of the same town were enrolled in the study. The hospitals were selected in such a way that each level of the health pyramid was represented. Pharmacies were randomly selected from a list of pharmacies in the same city. The study focused on General Practitioners and specialists, Pharmacists, Dentists, Nurses and Midwives. Also included were all HP working in a clinical unit or at a pharmacy and having the ability to detect and notify an ADR.A stratified random sampling technique was used in this study and a survey was conducted using a pre-tested self-administered questionnaire with a validity index of 0.97 . This questionnaire was structure as follow: 17 questions with 8 (20 items) destined to assess knowledge, 4 for the assessment of attitudes and 5 devoted to practices.

Upon contact with the health practitioners (HP), eligibility was sought. The objectives of the study and the procedure were then presented to eligible HP for obtaining consent. Participants answered questions by filling out the technical form that was immediately collected by the investigators. A total of $330 \mathrm{HP}$ received the questionnaire.

The data collected were keyed into a computer the statistical software Epi-Info version 3.5.4 and the analysis performed by SPSS version 18.0 software and Microsoft Excel 2007 spreadsheet. To assess knowledge, 08 questions were asked to practitioners. Each right answer worth 1 (one) point; the maximum possible score was 20 points (20 items). The assessment of the level of knowledge held on the following criteria (Table 1).

Table I Knowledge level of appreciation criteria ${ }^{7}$

\begin{tabular}{ll}
\hline Score (points) & Appreciation \\
\hline$[0 ; 5]$ & Bad \\
{$[5 ; 10]$} & Insufficient \\
{$[10 ; 14]$} & Average \\
{$[15$ and above $]$} & Good \\
\hline
\end{tabular}

\section{Results}

Out of the $330 \mathrm{HP}$ who accepted to participate, 188 completely filled the questionnaire. The characteristics of the study sample are summarized in Table 2. The structure of our sample was close to that of Yerbanga et $\mathrm{al}^{8}$ conducted in Burkina Faso in 1999 and Palain and collaborators ${ }^{9}$ carried out in Nepal in 2010. Our sample had a sex ratio male/female of $3 / 7$. This could be explained by the fact that nearly three quarters of the participants were from a group of nurses where there was usually a female predominance. The distribution of the sample population of participants by profession or place of work was proportional to the weight of each establishment in the source population.

The characteristics of the study population sample as indicated in Table 3 showed that forty seven percent of physicians were aware of the ADR reporting activity in our sampled population. Seventy-eight participants out of 188 were aware of the existence of the National Pharmacovigilance Centre (NPVC). Among HP with knowledge of the ADR reporting system, there were about $54 \%$ of physicians. This result was similar to the proportion of $55 \%$ of doctors for the same variable in a study by DJITAFO and collaborators. ${ }^{10}$ It was a different from findings of Chopra et al.. ${ }^{11}$ in a study in India where the positive response rate was $73 \%$ among Physicians. ${ }^{3,11}$ This difference could be explained by the presence of a pharmaceutical environment more developed in India than in Cameroon.

Seventy-height percent of Pharmacists knew the NPVC against $56 \%$ Physicians, $32 \%$ and $30 \%$ for the cases Nurses and Midwives respectively. This difference in knowledge of NPVC was probably due to the fact that this NPVC was run by the Directorate of Pharmacy and Drug Board in the Ministry of Public Health which is the Direction of Pharmacy, Medicine and Laboratories (DPML) in Cameroon.

Forty four percent of participants (84 out of 188) interviewed responded that all HP were concerned with the ADR reporting. The WHO through the Uppsala Monitoring Centre recommends the involvement of all HP (GPs or specialists, pharmacists, dentists, midwives, nurses and other health professional who may prescribe or administer drugs) in reporting of adverse drugs events encountered during their practice. ${ }^{2,5}$

To the question of what information should be reported, 159 out of 188 participants answered adverse drugs reaction. In contrast, thirty participants $(16 \%)$ responded that the lack of or reduction in 
efficiency as well as drug poisoning and other problems associated with the use of drugs should also be notified. By definition, PV takes care of all the problems associated with drug use. ${ }^{8}$ "The notification of cases relating to lack of efficacy or quality defects of a drug is particularly recommended when there are manufacturing problems, counterfeit or resistance (antibiotics)". 5

Concerning the type of adverse effect to be reported, forty-four percent (eighty-four out of one hundred and eighty-eight) respondents that any side effects confirmed or suspected should be reported. Thirty percent (fifty-seven out of one hundred and eighty-eight) respondents thought that only proved adverse effect should be reported. Eighteen percent (thirty-five out of one hundred and eighty-eight) believed that adverse drugs effects indicated in the leaflet must be notified. These results are similar to those of Fadare et al. ${ }^{12}$ who conducted a similar study in Nigeria. In countries where PV is not yet well established, reporting of any adverse event coinciding with administration of a drug - known or unknown, serious or benign - is useful and necessary to create a 'reporting culture' allowing the development of reporting habit where any adverse reactions are suspected to be due to a drug. ${ }^{5}$

The mean knowledge score in our sample was $8.1 / 20$. Fortyfive respondents $(23.9 \%)$ had a very low level of knowledge (Knowledge score less than 5/20). Our results showed that health professionals surveyed have a lower level of knowledge than those in Nepal, Malaysia and Nigeria., ${ }^{9,13,14}$ The reasons for this could be inadequate training (basic and continuing) but also the lack of efficient organization of NPVC. Indeed, more than a decade after the launching of PV in Cameroon, NPVC did not have a tool for liaison with HP (as a pharmacovigilance bulletin for example) (Table 4).

Table 2 Characteristic of the study population sample

\begin{tabular}{|c|c|c|c|c|c|}
\hline \multirow[b]{2}{*}{ Profession } & \multicolumn{5}{|c|}{ Medical Health Structure } \\
\hline & $\begin{array}{l}\text { Yaoundé University } \\
\text { Teaching Hospital }\end{array}$ & $\begin{array}{l}\text { Yaoundé Central } \\
\text { Hospital }\end{array}$ & $\begin{array}{l}\text { Efoulan District } \\
\text { Hospital }\end{array}$ & $\begin{array}{l}\text { Community } \\
\text { Pharmacy }\end{array}$ & Total (\%) \\
\hline Medical Doctors & 13 & 31 & 6 & 0 & $50(26.6)$ \\
\hline Pharmacist & 0 & 1 & 0 & 13 & $14(7.4)$ \\
\hline Dentists & $\mathrm{I}$ & 1 & 0 & 0 & $2(I . I)$ \\
\hline Nurses & 53 & 37 & 22 & 0 & $112(59.6)$ \\
\hline Midwives & $\mathrm{I}$ & 7 & 2 & 0 & $10(5.3)$ \\
\hline Total & 68 & 77 & 30 & 13 & 188 \\
\hline
\end{tabular}

The study received ethical clearance from the Faculty of Medicine and Biomedical Sciences Institutional Review Board (FMBS-UYI/IRB/20I4).

Table 3 Answers to some questions evaluating knowledge

\begin{tabular}{lllll}
\hline & \multicolumn{2}{l}{$\begin{array}{l}\text { Know the Existence of the Activity of Adverse } \\
\text { Drugs Reactions Reporting }\end{array}$} & \multicolumn{2}{l}{$\begin{array}{l}\text { Know the Existence of the National } \\
\text { Pharmacovigilance Centre }\end{array}$} \\
\cline { 2 - 5 } Medical Doctors & No & Yes & No & Yes \\
Pharmacists & 23 & 27 & 22 & 11 \\
Dentists & 6 & 8 & 3 & 0 \\
Nurses & 2 & 0 & 2 & 36 \\
Midwives & 64 & 48 & 7 & 3 \\
Total & 4 & 6 & 110 & 78 \\
\hline
\end{tabular}

Table 4 Mean knowledge score

\begin{tabular}{lll}
\hline Profession & Sampled Population & Mean Score/20 \\
\hline Physician & 50 & 9.1 \\
Pharmacist & 14 & 10.57 \\
Dentist & 2 & 2 \\
Nurses & 112 & 7.5 \\
Mid-wives & 10 & 7.4 \\
Total & 188 & 8.1 \\
\hline
\end{tabular}

Table 5 Places of reporting

\begin{tabular}{|c|c|c|c|c|c|c|}
\hline & Colleagues & Medical Delegates & Hierachy & Scientific JournalsPrescriptor & CNPVI MINSANTE & Total \\
\hline $\mathrm{N}$ & 2 & II & 2 & $\begin{array}{ll}1 & 42\end{array}$ & I & 59 \\
\hline (\%) & $(3,4)$ & $(18,7)$ & $(3,4)$ & $(7 I, I)$ & $(I, 7)$ & -100 \\
\hline
\end{tabular}

Pharmacists had an average level of knowledge. The same finding had been made in similar studies. ${ }^{10,15}$ In fact, they are more likely to be exposed to PV during their early professionalizing trainings. Health professionals surveyed have recognized almost unanimously $(94.7 \%)$ that ADR reporting was necessary. Similarly, one hundred and seventy-one practitioners out of one hundred and eighty-eight believed that this activity should be obligatory. This "right" attitude was shared by other HP who practiced in other countries. ${ }^{8,9,16,17}$. The majority of respondents would like to receive a feedback from the NPVC, information on what to do $(118 / 188)$ when they report an ADR. They would also like to receive more information on the reported adverse event $(75 / 188)$. In both cases, there was a desire to receive feedback when a reporting was made. Since attitudes underlie practices, it may be wise for NPVC to incorporate into its strategies to stimulate PV, a systematic feedback to the reporter.

One hundred and fifty-five respondents out of one hundred and eighty-eight said they had been confronted with ADR, but only $38.1 \%$ 
(fifty-nine out of one hundred and eighty-eight) reported having notified the adverse reaction diagnosed to a third parties or NPVC. The same patterns were found in the HP in similar studies.

Places of reporting were the physician/prescriber $(71.1 \%$; forty-two respondents out of fifty-nine), medical representatives (18.8\%; eleven respondents out of fifty-nine), colleagues (3.4\%; two respondents out of fifty-nine), and the hierarchy (3.4\%; two respondents out of fifty-nine). One point seven percent of reports (one respondent out of fifty-nine) were made to NPVC, which represented a reporting rate of $0.65 \%$. The low proportion of notifications to the NPVC was a significant indicator of the need for awareness of HP on PV. In Burkina Faso in $1999,{ }^{8} 21 \%$ of reports were made by the physicians $(45.8 \%$ of reports from Nurses) and $62 \%$ to medical representatives against only $5 \%$ addressed to the Directorate of pharmaceutical services (Table 5).

According to our respondents the absence of the ADR reporting form $(70.4 \%)$ and ignorance of the type of ADR to be reported $(24.8 \%)$ were the main reasons for non-reporting. The mildness of the observed effect and the uncertainty of the diagnosis accounted for $16.5 \%$ and $13.8 \%$ of the reasons for non-notification respectively. Given these results, we can say that the barriers to communication in our context were found in the first two categories of Vallano et al. ${ }^{18}$

\section{Conclusion}

Knowledge, attitudes and practices (KAP) of Cameroon's Health Professionals towards Adverse Drug Reactions reporting were poor. The ADR reporting rate was $0,65 \%$. The was the need for further education of Health Professional in the area of pharmacovogilance and better organization of the National Pharmacovigilance Centre thus seems to be priority areas where active intervention is need. The awareness and advocacy of pharmacovigilance in Cameroon is important for the public health sector in the promotion of drug safety and management within the framework of the Drug development portfolio. PHV studies are geared towards promoting the rational and safe use of medicines within the framework of early detection of unknown safety problems, detection of increases in frequency, identification of risk factors quantifying risks, preventing patients from being affected unnecessarily.

\section{Authorship contribution}

All authors contributed to the designing, preparation, editing, and final review of the manuscript.

\section{Acknowledgements}

Authors thank the collaborators of their respective institutions for the comments on the manuscript.

\section{Conflicts of interest}

The authors declare no conflicts of interest related to this article.

\section{Funding}

None.

\section{References}

1. http://www.who.int/medicines/areas/quality_safety/safety_efficacy/ pharmvigi/en/
2. ISBD. La déclaration de Berlin sur la pharmacovigilance. Rev Prescrire. $2005 ; 2: 1-8$

3. Lazarou J, Pomeranz BH, Corey PN. Incidence of adverse drug reactions in hospitalized patients:a meta-analysis of prospective studies. JAMA. 1998;279(15):1200-1205.

4. Kongkaew C, Noyce PR, Ashcroft DM. Hospital admissions associated with adverse drug reactions:a systematic review of prospective observational studies. Ann Pharmacother. 2008;42(7):1017-1025.

5. UMC. Surveillance de la sécurité d'emploi des médicaments:Guide pour la création et le fonctionnement d'un centre de pharmacovigilance. 2000 .

6. Biron P. La pharmacovigilance de A à Z. Montréal. Département de pharmacologie. 1999;1(1):315.

7. ESSI MJ, Njoya Oudou. L'Enquête CAP (Connaissances, Attitudes, Pratiques) en Recherche Médicale. Health Sci Dis. 2013;14(2):1-3.

8. Yerbanga Tegwende M. Etude sur la pratique de la pharmacovigilance au Burkina Faso:état de réalisation à Ouagadougou. Cameroon: [Thèse de doctorat en Pharmacie]. Université d'Ouagadougou, Faculté des Sciences de la Santé; 1999.

9. Palaian S, Ibrahim MI, Mishra P. Health professionals' knowledge, attitude and practices towards pharmacovigilance in Nepal. Pharm Pract. 2011;9(4):228-235.

10. Djitafo Fah BA, Wouessidjewe D. Etat des lieux de la pharmacovigilance au Cameroun [Thèse de doctorat en Pharmacie]. Cameroon:Université Des Montagnes; 2013.

11. Chopra D, Wardhan N, Rehan HS. Knowledge, attitude and practices associated with adverse drug reaction reporting amongst doctors in a teaching hospital. Int J Risk Saf Med. 2011;23(4):227-232.

12. Fadare JO, Enwere OO, Afolabi AO, et al. Knowledge, attitude and practice of adverse drug reaction reporting among healthcare workers in a tertiary centre in Northern Nigeria. Tropical Journal of Pharmaceutical Research. 2011;10(3):235-242.

13. Agarwal R, Daher AM, Mohd Ismail N. Knowledge, practices and attitudes towards adverse drug reaction reporting by private practitioners from Klang valley in malaysia. Malays J Med Sci. 2013;20(2):52-61.

14. Oshikoya KA, Awobusuyi JO. Perceptions of doctors to adverse drug reaction reporting in a teaching hospital in Lagos, Nigeria. BMC Clin Pharmacol. 2009;9:14.

15. Irujo M, Beitia G, Bes-Rastrollo M, et al. Factors that influence underreporting of suspected adverse drug reactions among community pharmacists in a Spanish region. Drug Saf. 2007;30(11):1073-1082.

16. Figueiras A, Tato F, Fontaiñas J, et al. Physicians' attitudes towards voluntary reporting of adverse drug events. J Eval Clin Pract. 2001;7(4):347-354.

17. Prakasam A, Nidamanuri A, Kumar S. Knowledge, perception and practice of pharmacovigilance among community pharmacists in South India. Pharm Pract. 2012;10(4):222-226.

18. Vallano A, Cereza G, Pedròs C, et al. Obstacles and solutions for spontaneous reporting of adverse drug reactions in the hospital. $\mathrm{Br} J$ Clin Pharmacol. 2005;60(6):653-658. 